OSGOOD, C, E. \& HEYER, A. W.. JR. A new interpretation of figural after-effects. Psychological Review, 1951, 59, 98-118.

RESTLE, F., \& MERRYMAN, C. Distance and an illusion of length of lines. Joumal of Experimental Psychology, 1969,81, 297-302.

VIRSU, $V$, Geometric illusions as categorization effects: A system of interpretation. Suomalaisen
Tiedeakatemian Toimituksia Annales Academiae Scientiarum Fennicae. 1968. 154, 1-73.

WINER, B. J. Statistical principles in experimental design. New York: McGraw-Hill, 1962. NOTE

1. Howard, R. B. Neurophysiological models of figural aftereffects and visual illusions. In preparation. Prepublieation copies of this paper are available from the autbor upon request.

\title{
Effects of ratio of win-stay to lose-shift problems on children's performance on win-stay problems*
}

\author{
PHYLLIS W. BERMAN \\ The Pennsylvania State University, University Park, Pa. 16802 \\ and \\ JOHN MYERS, University of Miami, Coral Gables, Fla. 33133
}

Statistical analyses combined data from a series of learning-set experiments with 4- and 8-year-old children (Berman, 1965; Berman, Rane, \& Bahow, 1970). Two types of two-trial discrimination problems were presented: win-stay and lose-shift problems. The proportion of win-stay to lose-shift problems differed for four experimental groups. A significant win-stay practice effect was demonstrated when increasing numbers of win-stay problems were added to a constant number of nonreward problems. Two analyses tested the effect of adding lose-shift problems to a constant number of win-stay problems. The lose-shift problems significantly interfered with performance on win-stay problems.

In a series of learning-set experiments (Berman, 1965; Berman, Rane, \& Behow, 1970), two types of two-trial discrimination problems were presented to children. A single stimulus was presented on Trial 1 and then again on Trial 2, paired with a new stimulus. When the Trial 1 stimulus was rewarded (win-stay or reward problems), the $S$ was required to choose it again on Trial 2 . When it was not rewarded (lose-shift or nonreward problems), he was required to choose the new stimulus on Trial 2. The proportion of win-stay to lose-shift problems given per day differed for four experimental groups. Group 25 was given $25 \%$ reward problems; Group 50, 50\%; Group 75, $75 \%$; and Group 100, 100\%. The procedure was similar to that used by King \& Harlow (1962) with monkeys.

When 4- and 8-year-old Ss had an equal number of problems of each type (Berman, Rane, \& Bahow, 1970), they made significantly more errors on the win-stay problems. When the problems were given in unequal proportions (Berman, 1965), varied experience with the two problems only slightly affected performance on

\footnotetext{
* The research reported was carried out while the first author was at the University of Wisconsin and was supported by the Cooperative Research Program of the Office of Education, United States Department of Health, Education, and Welfare.
}

the lose-shift problem but greatly affected performance on the more difficult win-stay problem. The effect of varied experience on win-stay performance may be due to either or both of two factors: positive transfer resulting from practice with the win-stay problem and negative transfer resulting from, reward of shift responses which are correct on lose-shift problems but incorrect on win-stay problems. The present analyses test each of the two factors separately, while holding the other constant.

\section{SUBJECTS}

The Ss were 32 4-year-olds and 32 8-year-olds. Names of Ss were drawn from lists of children living in University of Wisconsin housing projects for faculty and graduate students, from registration lists of a recreation program of a nearby elementary school, and from two nursery schools. Children were selected randomly within age groups but were limited to children of graduate students, faculty members, and others with professional and managerial occupations. Four children failed to complete the series of experimental sessions, two due to illness and two because of reluctance to participate. They were replaced by others from the same age groups. Mean ages of the 4-year-old groups were: Group 25, 53 months; Group 50, 52 months: Group 75, 55 months; and Group 100, 53 months. Mean ages of the 8-year-old groups were: Group 25, 100 months; Group 50, 101 months; Group 75, 101 months; and Group 100, 101 months.

APPARATUS AND STIMULI

A simplified form of the Wisconsin General Test Apparatus (Harlow, 1959) was used. Stimuli were 288 stereometric "junk objects," varying in many dimensions, such as form, color, pattern, and material. Two new objects were used as stimuli for each two-trial problem, with stimuli presented in different randomly selected pairs and in a different order for each $S$. Stimuli were presented on a $5 \frac{1 / 4}{4} \times 17 \frac{3}{4}$ in. tray, with three reward wells which were 6 in. apart from center to center.

\section{PROCEDURE}

Within each age group, eight children were chosen and assigned randomly to each of the procedural groups. Groups 25, 50, and 75 received 144 problems. Group 25 had $25 \%$ reward problems (6 reward and 18 nonreward problems per day for 6 days); Group 50 had 50\% (12 reward and nonreward problems per day for 6 days); Group 75 had 75\% (18 reward and 6 nonreward problems for each of 6 days). Group 100 had 108 reward problems only ( 24 problems per day for 4 days and 12 on the fifth day).

On Trial 1 of reward problems, a single object was placed over the center well of the tray. The well contained a small toy. On Trial 2, the same stimulus covered one of the side wells and its choice was again rewarded. It was paired with a new stimulus which covered the other empty side well. On nonreward problems, the same procedure was followed, except that the single stimulus presented on Trial 1 was not rewarded on either trial and the novel stimulus with which it was paired on Trial 2 was rewarded.

Each child was seen individually. On Trial 1 he was asked to see if the stimulus presented had a toy beneath it. On Trial 2 he was told, "One of these has a toy under it. Pick the one you think has a toy under it." After his choice, he was told, "Yes, the toy was under that one, wasn't it?" (or, "No, the toy was not under that one, was it?"). Twenty-four problems per day were presented for 6 days $\left(4^{1 / 2}\right.$ days for Group 100), or until the $S$ met a criterion of correct responses to 10 consecutive reward problems and 10 consecutive nonreward problems.

The presentation order of reward and nonreward problems was determined randomly within restrictions designed to reduce long runs of either of the problems. Position of reward on Trial 2 was 
balanced and also randomized within restrictions designed to limit long runs of problems with the reward in either the right or the left position.

\section{RESULTS AND DISCUSSION}

Reward problem practice effects were tested by comparing the win-stay performance of three groups, each of which had been given 36 nonreward problems but a varying number of reward problems. Figure 1 shows, for each group, mean scores on those reward problems which were int erspersed among the first 36 nonreward problems administered to the group; i.e., 12, 36, and 108, for Groups 25, 50, and 75 , respectively. The scores used for this comparison were for Days 1 and 2 for Group 25 , Days 1,2 , and 3 for Group 50, and Days 1.6 for Group 75. When number of nonreward problems was held constant, practice with reward problems was a significant variable $(F=12.806, \mathrm{df}=2 / 42, \mathrm{p}<.001)$. The effect appeared to be due to the superior performance of Group 75. Both Group 25 and Group 50 had win-stay scores not much above the $40 \%$ level.

The effect of experience with lose-shift problems on win-stay performance was evaluated in two ways. A comparison was made between Groups 75 and 100, and another comparison was made using the win-stay data of all four groups for 36 reward problems, each with a different number of nonreward problems. Groups 75 and 100 had each been given 108 reward problems with the same procedures. However, Group 100 was given only reward problems, while Group 75 was given 36 additional nonreward problems interspersed among the reward problems. The 4- and 8-year-olds of Group 100 respectively solved a mean of $77 \%$ and $92 \%$ of the reward problems. In contrast, Group 75 4-year-olds solved only an average of $66 \%$ reward problems correctly, and the 8-year-olds of that group solved only $71 \%$ of the reward problems correctly.

The scores were converted with an arc sin transformation to reduce heterogeneity of variance resulting from the many nearly perfect scores in Group 100 and were submitted to analysis of variance. Group 75 made significantly more errors on the win-stay problems than did Group 100 $(\mathrm{F}=7.377, \mathrm{df}=1 / 28, \mathrm{p}<.05)$. The inferior performance of Group 75 was assumed to be the effect of negative transfer from the reward of shift responses which were correct on the 36 nonreward problems but incorrect on the reward problems. Age was not a significant variable, and there was no interaction between age and group.

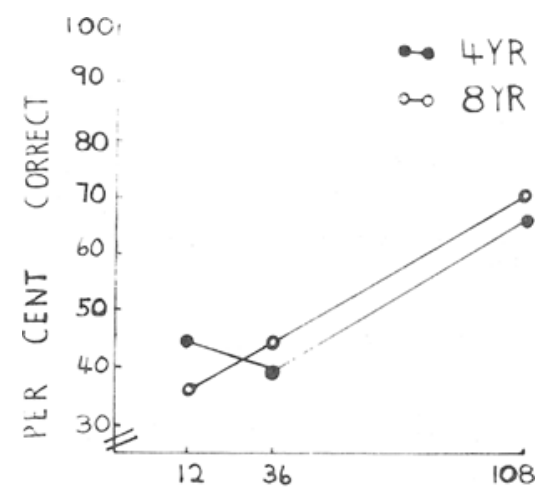

\section{NUMBER OF REWARD PROBLEMS}

Fig. 1. Mean scores on reward problems of three experimental groups. Each group was given a different number of reward problems interspersed among 36 nonreward problems. Scores are in percent correct for 4-and 8-year-olds.

The effects of experience with lose-shift problems were further evaluated by comparing the reward performances of four groups which had increasing numbers of nonreward problems. Figure 2 shows percent of correct reward problems for each of the groups. The scores used were for the first 36 reward problems administered to each group. The number of nonreward problems interspersed among these 36 reward problems were: 0 for Group 100, 12 for Group 75, 36 for Group 50, and 108 for Group 25. Scores were from Days 1 and 2 for Groups 100 and 75, Days 1-3 for Group 50, and Days 1-6 for Group 25.

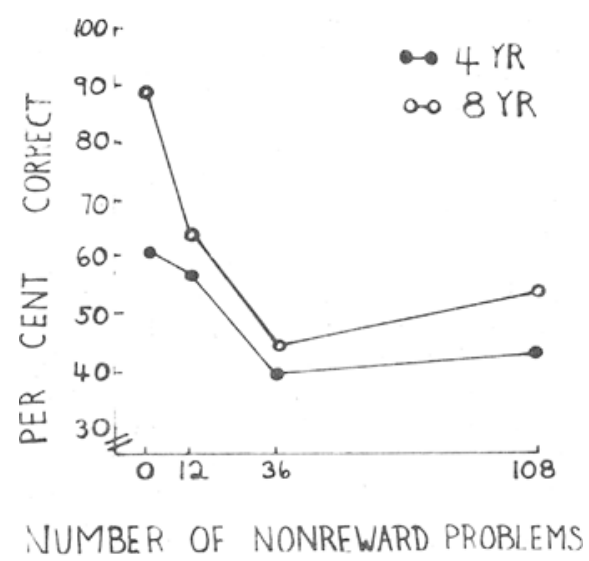

Fig. 2. Mean scores on 36 reward problems of four experimental groups. Each group was given a different number of nonreward problems interspersed among 36 reward problems. Scores are in percent correct for 4- and 8-year-olds.
As the number of nonreward problems increased from 0 to 12 to 36 , children made more shift errors in response to reward problems. However, children with 108 nonreward and 36 reward problems made no more errors on the reward problems than those who had 36 problems of each type. Analysis of variance showed two variables to be significant: age $(F=8.845$, df $=1 / 56$, $\mathrm{p}<.01$ ) and number of nonreward problems $(F=11.795, \quad \mathrm{df}=3 / 56$, $\mathrm{p}<.001)$. There was no significant interaction between the two variables.

King and Harlow found, with monkeys, that learning was not specific to the reward condition within a problem but was dependent upon the ratio of problems with Trial 1 reward to those with Trial 1 nonreward. This is also true of 4- and 8-year-old children. The present analyses demonstrate that win-stay performance is dependent, not only on the amount of experience with reward problems, but also on the amount of experience with nonreward problems. The tendency to shift choice on Trial 2 was rewarded on nonrewarded problems and generalized to situations when it was incorrect to shift, i.e. reward problems. The addition of even a few nonreward problems significantly augmented the strong tendency to shift choice following reward. In contrast, the tendency to perseverate choice on nonreward problems was weak, and the ratio of reward to nonreward problems had little effect on lose-shift performance. An analysis of lose-shift performance, combining data from Groups 25, 50, and 75, showed only a small nonsignificant effect of increasing the number of nonreward problems (with 12,36 , or 108 nonreward problems to 36 reward problems). Similarly, the addition of increasing numbers of reward problems to a constant number of nonreward problems had no significant effect on lose-shift performance (with 12,36 , or 108 reward problems to 36 nonreward problems).

\section{REFERENCES}

BERMAN, P. W. A study of children's error tendencies during learning. Cooperative Research Project No.S-210, United States Office of Education. 1965.

BERMAN, P. W., RANE, N. G., \& BAHOW, E. Age changes in children's learning set with win-stay, lose-shift problems. Developmental Psychology, 1970, 2 , 233-239.

HARLOW, H. F. Learning set and error factor theory. In S. Koch (Ed.). Psychology: A study of a science. Vol. 2. New York: McGraw-Hill, 1959.

KING, J. E., \& HARLOW, H. F. Effect of ratio of Trial 1 reward to nonreward on the discrimination learning of macaque monkeys. Journal of Comparative \& Physiological Psychology, 1962, 55, 872-875. 